Research Article

\title{
La culture du maïs face au binôme coton-anacarde dans le nord ivoirien: Une cohabitation dominée par les cultures de rente dans la Sous-Préfecture de Napié
}

\author{
OUATTARA Nanfouhoro Paul-Kévin, KOUAKOU Kouassi Olivier
}

\author{
Enseignant-Chercheur \\ Université Péléforo Gon Coulibaly de Korhogo (Côte d’Ivoire), Département de sociologie, BP 1328 \\ Korhogo, \\ Etudiant \\ Université Péléforo Gon Coulibaly de Korhogo (Côte d’Ivoire), Département de sociologie
}

\begin{abstract}
Resume
La culture du maïs est importante aussi bien pour l'homme que pour le développement de l'élevage. Mais, face à l'adoption et à la promotion de nouvelles filières agricoles dans le nord ivoirien, la production de maïs y est menacée. En effet, le coton, la mangue et surtout l'anacarde ont conduit à une pression foncière au détriment des cultures vivrières notamment le maïs. La présente étude qui s'est déroulée dans la région de Korhogo a pour objectif de connaitre les comportements des agriculteurs vis-à-vis des cultures de rente au regard du fait que le maïs constitue la nourriture de base du peuple senoufo. La démarche mixte de type qualitatif et quantitatif a été adoptée pour la collecte des données. Les entretiens individuels ainsi que des entretiens de groupe ont été réalisés à Djonkaha et Pimankaha dans la Sous-Préfecture de Napié. L'étude a permis de comprendre que la filière maïs bénéficie d'un faible appui. Elle note également que les cultures de rente ont permis aux paysans d'améliorer leurs conditions de vie. De plus, ces derniers bénéficient d'appuis techniques et financiers qui ont renforcé leur attachement à ces cultures. Cette situation a conduit progressivement à la réduction des terres dédiées au vivrier et au maïs en particulier augmentant ainsi le risque de vulnérabilité des paysans.
\end{abstract}

Mots-clés : Maïs, Anacarde, Coton, agriculture, Korhogo, Côte d'Ivoire.

\begin{abstract}
Maize cultivation is important both for humans and for the development of animal husbandry. But, faced with the promotion and development of new agricultural sectors in the north, maize production is threatened in this region. In fact, cotton, mango and above all cashew have led to land pressure to the detriment of food crops, particularly corn. The present study, which took place in the Korhogo region, aims to understand the behavior of farmers towards cash crops with regard to the fact that maize constitutes the staple food of the Senufo people. The mixed qualitative and quantitative approach was adopted for data collection. Individual interviews as well as group interviews were carried out in Djonkaha and Pimankaha in the Sub-Prefecture of Napié. The study revealed that the maize sector receives little support. She also notes that cash crops have enabled farmers to improve their living conditions. In addition, they benefit from technical supervision and financial support which has reinforced their attachment to these cultures. This situation has gradually led to the reduction of land dedicated to food crops and maize in particular, thus increasing the risk of vulnerability for farmers.
\end{abstract}

Keywords: Maize, Cashew, Cotton, agriculture, Korhogo, Côte d'Ivoire.

\section{I- Introduction}

La Côte d'Ivoire fait partie des pays africains dont l'essentiel de l'économie est basée sur l'agriculture. C'est le secteur clé de son économie (Koffi, 2015). En effet, le pays dispose d'énormes potentialités agricoles. Les cultures d'exportation telles que le cacao, le café, le palmier à huile et l'hévéa sont cultivées dans les régions 
forestières du sud tandis que le coton, l'anacarde et la mangue sont produits au centre et au nord du pays. Cette diversité agricole a permis à la Côte d'Ivoire de connaître un certain développement économique. Hormis les cultures introduites pendant la période coloniale telles que le cacao, le café, le coton etc., on assiste ces dernières années à la promotion de nouvelles cultures notamment l'anacarde et la mangue dans le paysage agricole ivoirien. Celles-ci contribuent au développement économique et social des populations des régions bénéficiaires. Dans le nord du pays, on pratiquait déjà la cotonculture mais l'anacarde et la mangue sont venus compléter le tableau des cultures de rente. Ainsi, ces trois spéculations occupent presque la quasitotalité des surfaces cultivables de la zone. Selon la Compagnie Ivoirienne de Coton (COIC), la production du coton était de 122.600 tonnes à l'issue de la campagne (2017-2018) dans sa zone de Korhogo (AIP, 2018). Celle de l'anacarde est passée de 51.000 tonnes en 2019 à 91.000 tonnes en 2020 (Leroy, 2021). Quant à la production de la mangue fraîche, elle s'élevait à 35.000 tonnes sur une production ivoirienne totale d'environ 180000 tonnes par an (Pugnet, 2018). C'est le lieu d'indiquer que ces deux dernières cultures ont été introduites par l'Etat ivoirien dans le Nord en vue de renforcer le couvert végétal dans le cadre de la politique de lutte contre l'avancée du désert (Sinan et N'dri, 2016). Aujourd'hui, le constat est qu'au-delà de la valeur écologique, la mangue et l'anacarde ont acquis une valeur économique et connaissent un développement dans cette région. La filière anacarde a aussi connu des restructurations avec la mise en place de l'Autorité de Régulation du Coton Anacarde (ARECA) puis la création du Conseil du Coton et Anacarde (CCA). Celle de la mangue bénéficie de l'appui du FIRCA notamment dans le cadre de la lutte contre les mouches des mangues. L'occupation des terres cultivables réservées à la production de ces produits agricoles est révélatrice de cette réalité. Les prix d'achat bord champ du kilogramme de la noix de cajou, du coton graine ou de la mangue fraîche sont sans conteste la conséquence de la volonté étatique de l'encadrement de ce secteur agricole.

Dans cet environnement, quelle est la place des productions vivrières ? Ces dernières sont également aussi diverses que variées. Elles sont cultivées sur toute l'étendue du territoire national. Cependant, en dépit de l'existence d'organismes tels que le Centre National de Recherche Agronomique (CNRA), l'Agence Nationale d'Appui au Développement Rural (ANADER), l'Office de Commercialisation et de Promotion des Produits Vivriers (OCPV), l'Interprofession du Maïs de Côte d'Ivoire (IMCI) etc. et malgré la mise en place du Plan National d'Investissements Agricoles (PNIA), elles semblent marginalisées. A l'échelle des politiques agricoles en Côte d'Ivoire, la filière maïs reste peu prioritaire (Rongead, 2014). Par exemple, alors que la culture du maïs jouit de bonnes conditions de production dans le nord, elle est de moins en moins pratiquée par les agriculteurs. Les paysans s'en détournent au profit des cultures de rente. Cette situation peut s'expliquer par le manque de politiques agricoles d'encadrement de l'Etat ivoirien à l'endroit des filières de cultures vivrières. Les prix d'achat incitatifs des produits des cultures de rente ainsi que l'encadrement dont ces dernières jouissent justifient pourquoi les paysans ont un intérêt moins marqué pour les cultures vivrières. Pourtant, les cultures vivrières que sont l'igname, le riz, le sorgho, l'arachide et le maïs ont toujours cohabité avec les cultures industrielles notamment le coton. Le développement des plantations de l'anacarde et de la mangue dans la région du Poro à davantage mis à mal les cultures vivrières. A cause du caractère pérenne de ces cultures, les terres réservées au vivrier en général et à la culture du maïs en particulier sont réduites dans le département de Korhogo. Cette tendance a pris de l'ampleur durant ces dernières décennies et la sous-préfecture de Napié est très marquée par ce phénomène. Or, au regard des habitudes culinaires et alimentaires, les productions vivrières particulièrement le maïs, constituent la base de l'alimentation des populations locales. C'est une culture essentielle dans la vie quotidienne et économique des ménages. Elle permet de satisfaire les besoins alimentaires des populations des villages comme celles des centres urbains. La production de maïs intervient également dans l'alimentation des animaux dans les fermes d'élevage. Lorsqu'on sait que les cultures de rente sont destinées à l'exportation et que le maïs est autoconsommé par la population locale, le fort intérêt des paysans pour ces cultures d'exportation soulève une préoccupation en termes d'autosuffisance alimentaire. Au regard de ces constats, il convient de connaitre les facteurs explicatifs des logiques des agriculteurs. Ainsi, cette étude veut connaitre les déterminants qui influencent les décisions des agriculteurs au détriment de la culture de maïs dans la Sous-Préfecture de Napié. 
OUATTARA Nanfouhoro Paul-Kévin et./al La culture du maïs face au binôme coton-anacarde dans le nord ivoirien: Une cohabitation dominée par les cultures de rente dans la Sous-Préfecture de Napié

\section{II- Methodologie}

L'enquête s'est déroulée dans les villages de Djadonkaha et Pimankaha dans la Sous-Préfecture de Napié. Le choix de cette zone d'étude répond à deux raisons principales. La première est que ces localités sont en zone rurale et la production du maïs dans ces deux villages est fortement impactée par les cultures de rente. La seconde est en rapport avec les habitudes alimentaires des nafara ${ }^{1}$, peuple autochtone de ces villages.

\section{Carte des villages enquêtés}

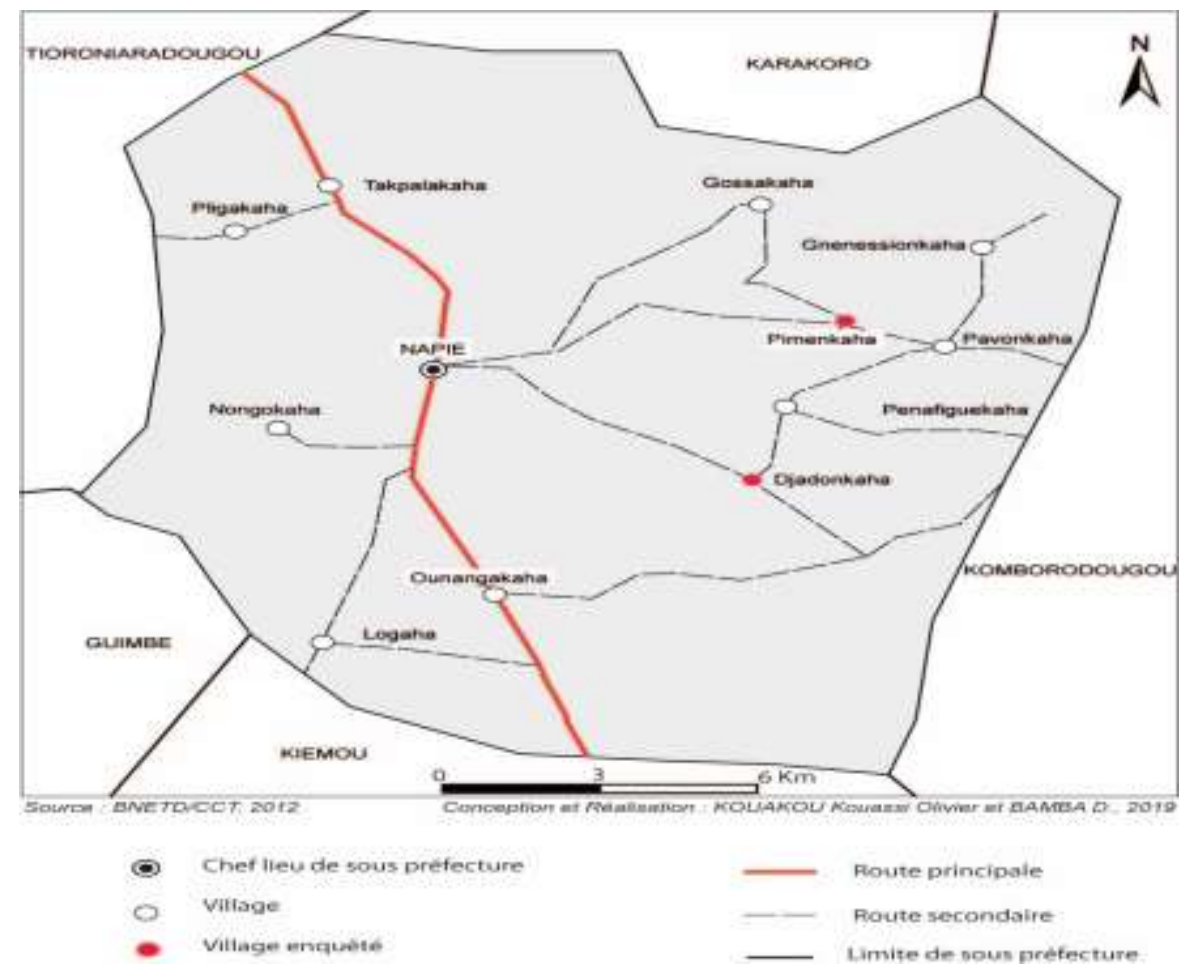

L'enquête s'est effectuée auprès des paysans, des responsables de coopératives agricoles et des agents d'encadrement agricole. La collecte des données a obéit à la fois à méthode qualitative et à la méthode quantitative. Pour faire partie des enquêtés de l'étude, il fallait être agriculteur et être cumulativement producteur d'anacarde, de coton et de maïs. En ce qui concerne les Conseillers Agricoles, ce sont les agents de l'Agence Nationale d'Appui au Développement Rural (ANADER) de la Zone de Korhogo qui ont été enquêtés. Finalement, ce sont au total 50 paysans dont 20 à Pimankaha et 30 à Djadonkaha qui ont été interrogés au moyen de questionnaire. Les responsables de coopérative l'ont été grâce à un guide d'entretien à travers un focus group. Les entretiens individuels ont eu lieu avec le personnel d'encadrement de l'ANADER. Ces rencontres ont été appuyées par des observations de terrain. Les données primaires ont été complétées par des informations de sources documentaires. Les interviews ont été enregistrées grâce au téléphone portable, retranscrites et traitées au moyen de la technique de l'analyse du contenu.

\section{III- Resultats}

\section{Impacts socio-économiques du binôme coton-anacarde}

L'agriculture est l'activité principale des populations de Napié au nord de la Côte d'Ivoire. Leurs principaux revenus agricoles proviennent essentiellement du coton et de l'anacarde. En effet, la culture de coton est ancrée dans les habitudes culturales des paysans de la zone d'étude depuis de longues années. Elle a contribué à améliorer les conditions socio-économiques des agriculteurs. Il en est de même pour celle de l'anacarde dont le développement a été rapide ces deux dernières décennies. L'impact de ces deux spéculations agricoles est visible dans plusieurs secteurs de la vie à Djadonkaha et Pimankaha.

\footnotetext{
${ }^{1}$ Les nafara sont les autochtones de la zone de l'étude. Ils font partie du peuple senoufo 
OUATTARA Nanfouhoro Paul-Kévin et./al La culture du maïs face au binôme coton-anacarde dans le nord ivoirien: Une cohabitation dominée par les cultures de rente dans la Sous-Préfecture de Napié

\subsection{Impacts du coton et de l'anacarde sur l'habitat et le cadre de vie}

La contribution de l'agriculture de rente dans les villages enquêtés se perçoit au niveau de l'habitat. Traditionnellement, les maisons dans les villages Senoufo sont de forme circulaire avec des murs en terre battue. L'intérieur de ces bâtisses est enduit d'argile mélangée à de la bouse de vache. La toiture est faite en paille. Grâce au coton et à l'anacarde, le type d'habitat a changé. Les habitations sont faites de plus en plus avec des briques en ciment, les toitures sont en tôles ondulées, les sols et l'intérieur sont enduits de ciment. Les murs sont parfois peints avec de la peinture industrielle. Pour le senoufo en général, les paysans nafara en particulier, la maison représente une valeur sociale. C'est un signe distinctif de richesse et de prestige. Ainsi, lorsqu'ils en ont la possibilité, ils se bâtissent des maisons. Aujourd'hui, les paysans nantis préfèrent les maisons en briques et en tôles pour leur durabilité et leur solidité. Ce choix est également justifié par son confort et pour l'estime sociale qu'elle procure. Le nombre de maisons en matériaux durables augmente en fonction de l'importance de la culture du coton dans le système cultural et des revenus qu'elle permet d'avoir. Voici ce qu'en dit un enquêté de Pimankaha :

"Avant je faisais le maïs. Le bénéfice que je gagnais ne peut pas construire de maison. Maintenant je cultive le coton, ce que je gagne m'a permis de construire ma maison ici au village et de construire deux autres à Napié ville et à Korhogo. Donc, je ne dors plus dans la case. On a réservé la case comme magasin pour garder les matériels de travail»

On le voit, la culture du coton contribue à améliorer la structure de l'habitat rural. Mais, celle de l'anacarde n'est pas en reste. Elle présente les mêmes avantages économiques ainsi que les mêmes impacts socioéconomiques que le coton. Elle contribue également à l'amélioration des conditions et du cadre de vie des producteurs dans les villages de la sous-préfecture de Napié. Les revenus tirés de la vente de la noix de cajou ont permis aux agriculteurs de construire des habitats de type moderne. Le changement positif au niveau du cadre de vie des producteurs est perceptible. Beaucoup de producteurs ont construit des maisons en dur couvertes de tôles. Les propos de cet enquêté confirment ce constat :

"L'anacarde nous permet aussi de construire nos maisons. A cause du bénéfice qu'on gagne, on ne dort plus dans les cases. On a construit des maisons en briques et couvertes de tôles».

Au regard de l'apport de la production de ces deux cultures au point de vue économique, on peut dire qu'elles représentent également une valeur sociale. De par leurs gains, elles contribuent au renforcement du statut social et à l'acquisition d'un nouveau statut social. La maison représentant un facteur de richesse en pays nafara.

En plus de cet impact notable sur les paysans au niveau de l'habitat et l'intégration sociale qu'elle induit, il faut noter l'incidence des cultures du coton et de l'anacarde au niveau des infrastructures routières. En effet, par le biais de l'ex Compagnie Ivoirienne de Développement des Fibres Textiles (CIDT) qui avait le monopole de la filière coton à Napié, le gouvernement ivoirien grâce à divers projets, a créé de nombreuses routes rurales. Après le zonage cotonnier, la Compagnie Ivoirienne de Coton (COIC), a pris la relève de ce processus de développement des infrastructures. Les pistes rurales relient les différents villages de la région et permettent d'écouler, non seulement, les productions de coton graine et de noix de cajou, mais aussi toutes sortes de production agricole vers les marchés ruraux ou urbains. Ces pistent facilitent également l'accès des villages aux personnes étrangères ainsi que la sortie des habitants du village vers l'extérieur. Elles sont entretenues grâce aux financements du CCA à travers notamment le défunt Projet d'Appui au Secteur Agricole en Côte d'Ivoire (PSAC). La création de ces infrastructures ainsi que les retombées financières du coton ont également contribué à faciliter la mobilité des agriculteurs. Grâce à leurs revenus, les paysans ont acheté des motos, des tricycles voire des voitures pour certains. Les déplacements sont ainsi plus au moins aisés sur les routes qui ne sont pas toujours praticables en toute saison pour les véhicules. Un agriculteur en témoigne en ces termes :

"Grâce à notre fidélité à la COIC et la CIDT, les routes de nos villages sont bien arrangées chaque année. Cela nous permet d'aller facilement et rapidement en ville pour faire nos courses et nos achats. 
OUATTARA Nanfouhoro Paul-Kévin et./al La culture du maïs face au binôme coton-anacarde dans le nord ivoirien: Une cohabitation dominée par les cultures de rente dans la Sous-Préfecture de Napié

Aussi, on a acheté nos motos pour nos déplacements. Et même les commerçants viennent facilement vendre dans nos villages».

L'apport du coton et de l'anacarde se ressent au niveau des pistes rurales. Les projets d'aménagement rural liés à ces spéculations ont permis l'ouverture des certaines voies et l'entretien des autres. L'Intercoton et le Conseil Coton-Anacarde en font un axe prioritaire dans la promotion de ces deux cultures dans les zones de production. Les échanges commerciaux des populations rurales avec l'extérieur se sont développés.

Outre l'habitat et la mobilité des populations, ces cultures ont permis la construction ou la réhabilitation d'infrastructures scolaires et sanitaires pour les populations. Par exemple, la culture du coton a contribué à augmenter le nombre d'écoles et le taux de scolarisation dans le Nord de la Côte d'Ivoire. Voici ce qu'en dit un enquêté responsable d'une coopérative de coton:

"Le coton que nous cultivons nous a permis de construire des écoles, des centres d'animations, des foyers de jeunes. Pendant la période culturale, les sociétés de coton envoient leurs agents sur le terrain dans notre village pour nous former et nous montrer l'usage des engrais et des produits phytosanitaires. En tout cas, on reçoit beaucoup de connaissances de la part de ces agents. Et, on arrive à mettre nos enfants à l'école ».

En ce qui concerne la santé des populations, il y a eu des changements. L'accès aux centres de santé est plus facile en termes d'infrastructures sanitaires et routières mais aussi grâce aux moyens financiers dont disposent désormais les paysans. Les accouchements des femmes enceintes se font à l'hôpital. Aujourd'hui, les femmes vont se faire examiner, parfois dès qu'elles sentent une anomalie. Avec le revenu tiré du coton et de l'anacarde, les populations arrivent à fréquenter les centres de santé et à se faire consulter normalement pour des soins. Un enquêté témoigne :

"Grâce à la culture du coton, on a des centres de santé et des dispensaires. Maintenant, nos femmes n'accouchent plus à la maison. Elles vont dans les centres de santé les plus proches pour des soins ».

En somme, le binôme coton-anacarde à une incidence positive sur le cadre de vie, la santé, la scolarisation des enfants, les pistes rurales. Les paysans ont ainsi pu acquérir des biens matériels qui ont amélioré leur vie quotidienne.

\subsection{Cultures du Coton et de l'anacarde : facteurs de création d'emplois ruraux et d'investissement}

En général, le milieu rural est peu attrayant, notamment pour les jeunes. Cela s'explique souvent par la rareté des emplois non agricoles dans ces localités. La pénibilité des travaux champêtres, essentiellement réalisés à l'aide d'outils manuels peu performants est un facteur supplémentaire rebutant qui entraîne l'exode des jeunes vers les centres urbains. Mais, on constate que, depuis leur introduction dans les systèmes de production agricole des régions des savanes, la culture du coton puis celle de la noix de cajou jouent un rôle appréciable dans la création de nouveaux emplois et/ou dans le renforcement d'emplois déjà existants. Du point de vue de la majorité des paysans, la culture du coton a entraîné l'augmentation du nombre d'exploitants agricoles. Les innovations techniques, notamment la culture attelée et les intrants chimiques performants, ont aidé à réduire la pénibilité du travail agricole. Elles ont aussi contribué à accroître le nombre d'exploitants et à réduire le chômage en milieu rural. De fait, le système d'encadrement agricole des producteurs du coton en particulier permet de créer des emplois. Les sociétés cotonnières recrutent du personnel au regard de l'augmentation du nombre des exploitants et des surfaces emblavées de coton chaque année. Le personnel salarié est composé de cadres et d'agents d'exécution permanents ou temporaires, travaillant au bureau et/ou sur le terrain. L'effectif du personnel augmente au fur et à mesure que le volume des activités s'accroît sur le terrain.

"Le coton nous donne du travail. Grâce au coton, nos enfants ne vont plus ailleurs pour se chercher. Quand la campagne du coton commence, la COIC et les autres sociétés de coton recrutent les jeunes pour travailler dans les usines. Et aussi, avec le peu qu'on gagne on prend les jeunes en groupe d'entraide pour nous aider. Il y a des jeunes du village qui sont des conseillers agricoles à la COIC». 
OUATTARA Nanfouhoro Paul-Kévin et./al La culture du maïs face au binôme coton-anacarde dans le nord ivoirien: Une cohabitation dominée par les cultures de rente dans la Sous-Préfecture de Napié

En plus du coton, la culture d'anacarde est une opportunité pour les agriculteurs de réaliser des projets personnels. Le développement ces dernières années de cette spéculation agricole dans le nord ivoirien a permis aux producteurs de réaliser plusieurs activités à savoir les mariages, l'achat de motos, de bœufs d'attelage, de motos tricycle, de postes téléviseurs, d'antennes paraboliques pour les téléviseurs, etc. Les charges familiales que sont la scolarisation des enfants, les soins de santé, l'habillement, les funérailles, les aides apportées aux membres de la famille et à la communauté sont devenus des actions faciles à supporter.

"Depuis qu'on fait l'anacarde, on gagne des bénéfices comme le coton. L'argent qu'on gagne nous permet de réaliser nos projets comme la construction de maisons, l'achat de moto et autres. Aussi, on arrive à mettre les enfants à l'école et à assurer leurs besoins».

L'apport du binôme coton anacarde est indéniable. Ces cultures sont omniprésentes dans le quotidien des paysans de Napié.

\subsection{Cultures du coton et de l'anacarde canaux de transfert de technologie en milieu rural}

Du point de vue personnel et individuel, l'encadrement agricole constitue un atout pour le binôme cotonanacarde. Chaque année, les producteurs de coton et de l'anacarde reçoivent des formations pour l'amélioration de la production et de la qualité de la production. Cet encadrement se fait au travers de conseils agricoles. Ils sont encadrés tant au niveau des techniques de production, des innovations de techniques agricoles qu'au niveau de la commercialisation de la production. Ces renforcements de capacité des paysans constituent un atout dans la modernisation du monde agricole à Djonkaha et à Pimankaha. En plus des aspects techniques, les producteurs de coton bénéficient de crédits agricoles. Ces soutiens se font au travers d'intrants agricoles qui vont des semences sélectionnées aux produits phytosanitaires. Par ailleurs, les prix d'achat des productions de ces deux denrées agricoles renforcent l'adhésion des paysans aux cultures du coton et de l'anacarde. En effet, si l'adoption de la première a été le fruit d'un effort intense et coordonné de l'administration, celle de la seconde s'est faite de façon spontanée. Dans tous les cas, ces spéculations bénéficient de la fixation de prix bord champ décidée par le gouvernement. Cela renforce la visibilité et la prévision des revenus par les paysans. Ces prix sont en évolution continue depuis les années 1990. Pour le coton, le prix du kilogramme est passé de 90 francs CFA en 1991 à 265 francs CFA en 2016. Sur la même période, le prix du kilogramme bord champ de la noix de cajou a varié de $85 \mathrm{~F}$ à $440 \mathrm{~F}$ (ARECA, 2016 cité par Silué et al, 2020).

En somme, tous ces atouts déterminent l'intérêt que les paysans ont pour les cultures de rente dans la zone de l'étude. Les revenus financiers, les infrastructures sociales de base, le mode d'encadrement et de soutien des agriculteurs surtout ceux du coton sont autant de facteurs qui expliquent en partie leur attachement et leur fidélité à ces cultures.

\section{La culture du maïs à Djadonkaha et Pimankaha}

\subsection{Avantages de la culture du maïs}

Les avantages liés à la production de maïs sont nombreux. En effet, cette denrée peut se consommer sous plusieurs formes à la fois par l'Homme et par les animaux. Dans l'alimentation humaine, le maïs est consommé sous forme de graines entières. Lorsqu'il est frais, les épis peuvent être bouillis. Dans ce cas, on parle de 'padégzour' en nafara. On peut simplement faire cuire les épis à la braise et les consommer. Les grains de certaines variétés sont éclatés et consommés sous le nom commun de «bon-maïs » dans le jargon populaire en Côte d'Ivoire. Ils servent d'amuse-bouche lors des repas. Les graines fraiches peuvent être préparées et consommées telle quelle ou entrer dans la préparation des repas en entrée. Le maïs peut être réduit en farine. Celle-ci est préparée sous forme de bouillies, de galettes cuites ou encore sous une forme plus compacte appelé "Kabatoh" en langue malinké. Par ailleurs, le maïs est aussi consommé sous forme de couscous. Les flocons de maïs sont préparés à partir de graines déshydratées et réduites en lamelles fines. Le maïs entre également dans la fabrication des aliments pour nourrissons en complément avec la farine de blé. Enfin, à partir de la fermentation, les grains de maïs servent à la préparation de boissons locales connue sous le nom de "tchapalo" ou de boissons industrielles telles que la bière, le whisky, etc. En ce qui concerne l'alimentation animale, la plante entière peut être consommée par le bétail comme fourrage frais ou sec. Le 
OUATTARA Nanfouhoro Paul-Kévin et./al La culture du maïs face au binôme coton-anacarde dans le nord ivoirien: Une cohabitation dominée par les cultures de rente dans la Sous-Préfecture de Napié

maïs est une plante d'élevage, elle permet donc d'engraisser plus rapidement les bovins et augmente ainsi la production de lait des vaches (Rongead, 2014). Il est utile dans l'élevage de volailles ou de porcins.

Au regard de ces atouts, des projets d'aide aux producteurs de maïs pilotés par le Fonds Interprofessionnel pour la Recherche et le Conseil Agricole (FIRCA) et le Projet d'appui à la Production Agricole et à la Commercialisation (PROPACOM) ont été initiés. Ces projets ont vu le jour mais n'ont pas toujours atteint des résultats probants au regard du désintérêt des bénéficiaires. Le tableau ci-dessous confirme cette situation.

Tableau : Production de maïs à Djadonkaha et Pimankaha en 2017 et 2018

\begin{tabular}{|l|l|l|l|}
\hline Villages d'enquête & Production en 2017 $(\mathbf{K g})$ & Production de 2018 \\
\hline Djadonkaha & 18535 & 10450 & \\
\hline Pimankaha & 13750 & 6160 & \\
\hline Total & $\mathbf{3 2 2 8 5}$ & $\mathbf{1 6 6 1 0}$ & \\
\hline
\end{tabular}

Source: Données d'enquête de terrain, 2019

Entre 2017 et 2018, le village de Djadonkaha a enregistré un recul de sa production d'environ 8 tonnes. Sur la même période Pimankaha a connu également une réduction de sa production à peu près dans les même proportions. Cette situation s'explique par plusieurs facteurs notamment les aléas climatiques qui conduisent à la mauvaise maitrise de la pluviométrie et à l'inorganisation de la filière maïs. Pour ce faire, les paysans produisent juste la quantité qui peut assurer leur besoins domestiques.

\subsection{Contraintes pédoclimatiques et sanitaires de la production de maïs}

L'incertitude joue un rôle particulièrement important en agriculture. La récolte peut varier du simple au double selon la météorologie. Si la période prévue pour la pratique culturale arrive alors qu'il n'y a pas de pluies, cela a une incidence sur la production. La culture du maïs à Djadonkaha et Pimankaha est assujettie aux aléas environnementaux et climatiques. Selon les enquêtés :

«Si le moment prévu pour la saison pluvieuse arrive, on commence à cultiver le maïs. Mais si la période de culture arrive et qu'il ne pleut pas, nous sommes obligés d'attendre la bonne saison pluvieuse. Et cela agit sur nos rendements à la fin de la saison».

Les activités agricoles liées à la culture du maïs commencent à partir du mois de mai avec les premières pluies dans la région nord du pays. Dans le cas contraire, ces travaux sont retardés afin d'attendre une période plus propice c'est-à-dire le moment où la pluie est suffisante pour préparer les sols. Les risques liés à la culture du maïs d'après les producteurs interrogés est sa grande dépendance à la qualité des sols et à la pluviométrie. Cela occasionnent des rendements aléatoires et nécessitent un apport important d'engrais minéraux sur les terres les plus pauvres. Les engrais chimiques proviennent des intrants fournis par la COIC qui est la structure d'encadrement agricole du coton de la zone. Ces fertilisants augmentent non seulement les coûts de production mais réduisent par la même occasion la marge de bénéfice des producteurs. Ainsi, les modes de production modernes alourdissent les charges de production. A Napié, la culture du maïs est assujettie également aux effets des ravageurs et à celle des maladies. En général, les attaques sur pied qui freinent la productivité du maïs en Côte d'Ivoire sont avant tout mécaniques. Les oiseaux lors des semis puis les mammifères durant la période de croissance et de la maturation des fruits constituent les principales sources de perte la production de maïs. Les oiseaux, notamment les perdrix consomment les graines mises en terre pour le semis. Les mammifères à savoir le bétail, les aulacodes consomment les jeunes pousses et les singes, les fruits en maturation. La protection contre ces destructions est contraignante pour de petits producteurs comme ceux de Djadonkaha et de Pimankaha. Les principales méthodes de lutte contre ces ravageurs est le gardiennage et la confection de barrière. Mais, ces options sont peu rentables pour les petites surfaces. Seuls quelques grands producteurs ont les moyens de les mettre en œuvre. Les attaques d'insectes sont également citées par certains producteurs mais ne représentent pas une limite importante à la productivité du maïs. En général, les rotations de cultures permettent de réduire le développement des populations d'insectes nuisibles (Rongead, 2014). Lorsque les insectes qui s'attaquent au maïs sur pied se 
OUATTARA Nanfouhoro Paul-Kévin et./al La culture du maïs face au binôme coton-anacarde dans le nord ivoirien: Une cohabitation dominée par les cultures de rente dans la Sous-Préfecture de Napié

produisent, les paysans utilisent les produits phytosanitaires destinés au cotonnier pour traiter les exploitations de maïs.

"Ya des maladies et des insectes qui attaquent le maïs. Ces deux années-là les bêtes nous fatiguent. On achète les produits pour traiter. On prend les produits de coton pour traiter».

En somme, la culture du maïs dépend en partie de celle du coton. C'est grâce à elle que les agriculteurs obtiennent des engrais et parfois des produits phytosanitaires pour améliorer la rentabilité de la production. C'est le paradoxe de ces deux spéculations. L'une par l'encadrement dont elle bénéficie permet en partie à l'autre de survivre alors qu'elle constitue un facteur qui l'empêche de se développer.

\subsection{Difficultés liées au stockage et à la commercialisation du maïs}

Le stockage du maïs est relativement facile selon les paysans. Les producteurs disent qu'ils peuvent le stocker facilement pendant un an lorsque le produit est bien séché. Il se fait dans des greniers traditionnels faits d'argile ou de banco et couverts de paille. Il peut se faire simplement sur des bois où les épis de maïs sont accrochés et exposés à l'air libre. Mais, le problème que les producteurs rencontrent dans le stockage du maïs est lié à la perte de poids causée par les charançons et insectes de farine. Ces pertes atteignent de 15 à $20 \%$ à partir du cinquième mois de stockage. C'est-à-dire que la longue durée de stockage a des effets sur les grains de maïs. Au-delà du sixième mois, il y a un développement d'insectes nécrophages et de moisissures responsables de la fabrication d'aflatoxine, substance nocive même pour l'alimentation animale. Lorsque les grossistes achètent le maïs, ils le stockent dans des magasins où ils empilent les sacs sur des palettes sans que les sacs touchent les murs pour éviter l'absorption de l'eau. Dès qu'il y a du soleil, ils en profitent pour étaler le produit pour le sécher pour en réduire l'humidité. Au besoin, ils recourent à l'usage de produits phytosanitaires pour conserver pour longtemps le maïs.

"Quand ça dure dans la maison les bêtes attaquent et ça fait perdre le poids du maïs. Cela est dî au fait qu'on n'a pas un marché propice pour évacuer rapidement notre produit ».

Ces propos relèvent les problèmes de l'écoulement de la production du maïs sur le marché. La commercialisation du maïs suit des canaux de commercialisation traditionnels en grande majorité informels et fondés sur la confiance. Le souci que rencontrent les producteurs de maïs est qu'ils n'ont pas de partenaires commerciaux fiables et stables pour la vente de leur production à l'échelle régionale et internationale. Ce ne sont que les acheteurs locaux qui font l'achat de leurs produits comme le confie un enquêté.

"Ce sont les acheteurs locaux qui font l'achat de nos maïs, aussi les femmes vont vendre dans les bassines au marché. Et ce qu'elles gagnent c'est pour acheter les condiments pour faire la sauce ».

En effet, la filière maïs n'a pas d'Organisation Professionnelle Agricole (OPA) qui puisse les encourager dans la production. Il n'y a non plus pas de structure comme pour le coton et l'anacarde avec le Conseil du Coton et de l'Anacarde ou à l'image du café et du cacao avec le Conseil du Café et du Cacao. Cela constitue une faiblesse pour la filière. Malgré la création de l'interprofession du maïs regroupant les transformateurs, les producteurs et les commerçants et transporteurs, la filière maïs peine à décoller. Au-delà des problèmes de stockage, le maïs connait une volatilité de son prix d'achat qui impacte l'écoulement de la production. En comparaison avec celui-ci de l'anacarde ou celui du coton, le prix d'achat du kilogramme de maïs n'est pas très incitatif. Il n'est non plus pas uniforme sur l'ensemble du territoire national. En plus de cela, ce prix n'est pas garanti par le gouvernement comme c'est le cas des cultures de rente citées plus haut. Cette situation n'encourage pas les agriculteurs. Selon le représentant des producteurs :

«Le prix du maïs est faible c'est à cause de ça on fait coton anacarde pour pourvoir assurer nos besoins. Souvent le prix est à 100 FCFA donc, ça ne nous arrange pas. On n'a de financements pendant la période de culture pour acheter engrais et les produits phytosanitaire». 
OUATTARA Nanfouhoro Paul-Kévin et./al La culture du maïs face au binôme coton-anacarde dans le nord ivoirien: Une cohabitation dominée par les cultures de rente dans la Sous-Préfecture de Napié

Les propos de cet enquêté traduisent le manque de motivation des maïsiculteurs en général et ceux de la zone de l'étude en particulier. Le graphique ci-dessous indique la variation des prix d'achat du Kilogramme de maïs de 2015 à 2018.

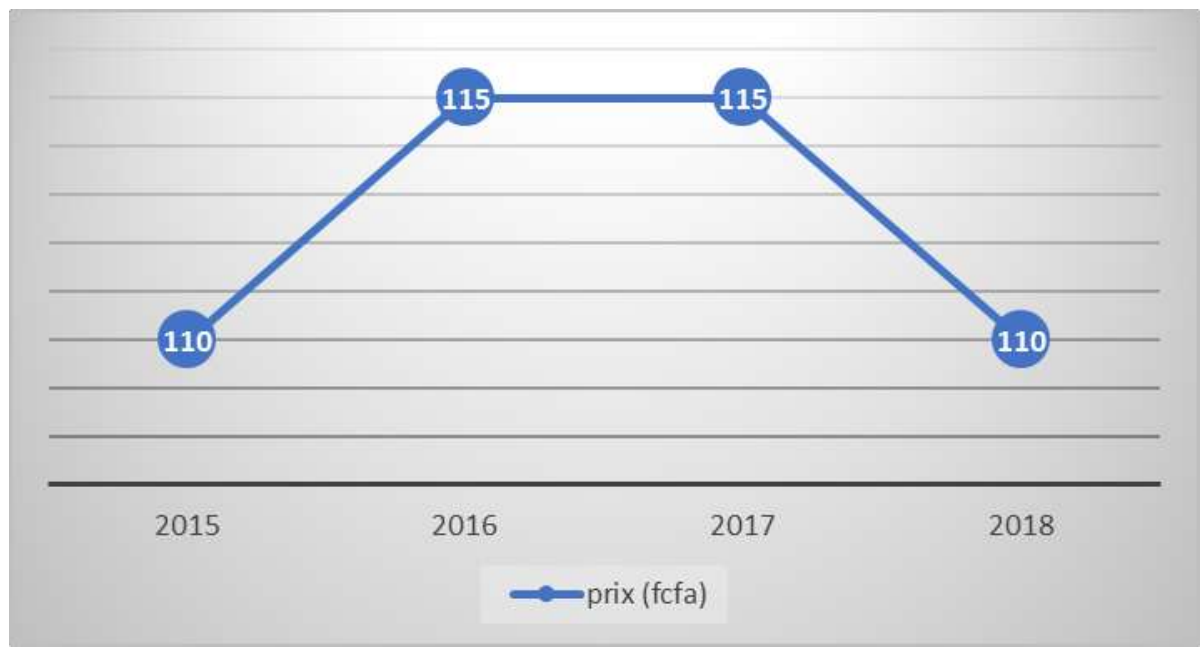

Figure : Variation des coûts du maïs de 2015 à 2018

Source : Données d'enquête, 2019.

Cette courbe indique l'évolution du prix auquel est acheté le maïs depuis 2015. On remarque que les années 2015 et 2018 présentent le même prix d'achat qui est 110f $/ \mathrm{kg}$. Tandis que la courbe est constante entre 2016 et 2017 avec un prix fixe de 115 F CFA le kilogramme. Ces prix d'achat du maïs sont quasiment la moitié de celui du coton. D'où le manque de motivation qui oriente les producteurs vers les spéculations agricoles rente qui dont les revenus sont plus stables.

"Le prix du maïs est faible et ça varie de $75 f c f a$ à 110fcfa. Quand, il y a un bon prix on sort pour vendre. Aussi quand on n'a pas une idée du prix ça nous met dans le doute ».

Cette réalité influence la production de maïs dans les localités de l'étude. Les bas prix d'achat, les coûts de production, la variation des prix d'une région à l'autre du pays, la faible implication de l'Etat dans la fixation des prix d'achat ainsi que l'étroitesse du marché n'incitent pas à la production de masse du maïs.

\subsection{Espace de culture, financement et encadrement des maïsiculteurs}

Les producteurs de maïs rencontrent des difficultés au niveau de l'encadrement et du financement. Il faut ajouter à cela les problèmes structurels et techniques tels que l'utilisation d'outils de travail rudimentaires. Ainsi, la faible production de cette denrée peut être liée également au coût des intrants. Ces derniers sont chers et les paysans ne bénéficient pas de subvention et de préfinancement comme c'est le cas avec le coton par exemple. En effet, l'absence de structures de préfinancement, de fournitures d'intrants et des produits phytosanitaires impacte significativement la production de maïs dans ces deux villages de la sous-préfecture de Napié. Cette contrainte est liée au fait que le FIRCA n'a pas de financement provenant de prélèvement sur la commercialisation du maïs. Elle agit par le biais du fonds de solidarité des exportations des cultures de rente car la filière maïs n'est pas une filière cotisante. Cela limite les actions de cette structure en direction des producteurs.

Le facteur de l'encadrement des producteurs n'est pas en reste. Les difficultés liées aux techniques de production sont en lien avec cette question. Dans les faits, dans la zone d'étude, les producteurs de maïs ne bénéficient pas d'un suivi technique particulier de la part des techniciens agricoles. Ce qui fait que les paysans n'adoptent pas de nouveaux outils ou de nouvelles techniques de production. Ils font usage des outils archaïques tels que la daba, la houe et la machette. La seule innovation utilisée par les paysans est la traction animale dans le cas de la culture attelée. N'ayant aucune formation, les producteurs de maïs de Napié n'ont pas une bonne connaissance de l'itinéraire agricole. Ils ont recours aux anciennes pratiques culturales empiriques ancestrales et rudimentaires. Selon les enquêtés, l'ANADER n'assure pas un 
encadrement réel et approprié aux paysans pour produire le maïs. Tout le système d'encadrement semble être orienté vers les cultures de rente. En effet, selon leur cahier de charge, les structures cotonnières notamment doivent assurer un suivi des cultures vivrières dans leur zone d'intervention. Ce qui fait que les producteurs qui parlent d'encadrement l'évoquent en rapport avec les conseils reçus par le biais des agents de COIC qui est la société cotonnière qui a en charge l'exploitation de la zone de l'étude. Ces derniers reçoivent des subventions d'intrants et des préfinancements pour la production. Toutefois, les structures d'encadrement ne s'attardent pas beaucoup sur les cultures vivrières dans leurs zones d'intervention. Cette opinion est contestée par un agent de l'ANADER qui affirme ce qui suit :

"La faible production du maïs est due à la non maîtrise de la pluviométrie, la cherté des intrants, la non application des techniques apprises, l'absence de structures de préfinancement des intrants et la non organisation de la filière maïs. Et aussi il n'y a pas de partenaires en tant que tel pour l'achat régulier du maïs».

Selon ce point de vue, les difficultés de la filière maïs à Djadonkaha et Pimankaha ne sont pas de leur ressort mais de celle des agriculteurs eux-mêmes. En fait, cette structure étatique selon ses missions, a en charge la formation des paysans aux bonnes pratiques agricoles, la sensibilisation à l'usage des semences sélectionnées, la gestion et l'usage des intrants (herbicides, engrais) et la sensibilisation des producteurs à se mettre en groupement. Malgré la mise en place de structures de recherche et d'encadrement agricole, certaines cultures telle que le maïs ne bénéficient pas nettement de ces politiques agricoles de l'Etat ivoirien. Des semences sont produites, mais elles ne sont pas suffisamment vulgarisées auprès des paysans en dehors de ceux qui sont dans des projets à financement nationaux ou à bailleurs internationaux.

En plus des facteurs notés plus haut, la réduction des terres dédiées à la culture de maïs constitue une réelle menace pour la survie de la production de maïs à Djadonkaha et Pimankaha. Pour comprendre cela, il faut interroger la pratique agricole endogène des agriculteurs de la région. En effet, la polyculture est traditionnellement le système d'exploitation agraire dans la zone d'étude. L'avènement du coton a consacré l'association de culture. Mais, l'adoption de la culture de l'anacardier a conduit à une mutation des habitudes agricoles en matière de l'usage du foncier. L'association se fait à la conquête d'un nouvel espace de culture. Le système de production évolue jusqu'à l'abandon de la parcelle à l'usage exclusif de l'anacarde. A Napié, la rotation de culture à base d'anacarde est la norme. De fait, la première année, les cultures de riz, de maïs, d'anacarde et/ou de coton sont pratiquées simultanément. Durant la deuxième année, le riz est retiré du système et est remplacé par l'arachide. A la troisième année, les légumes prennent la place de l'arachide et le coton disparait définitivement de cette association. En réalité, la compétition avec les jeunes plants d'anacardiers est néfaste pour un bon rendement de la production du coton et du vivrier. Finalement, l'exploitation est laissée au profit de l'anacarde car la taille des arbres ne favorisent plus la pratique d'autres cultures sur le même espace. Cette situation consacre la raréfaction des superficies dédiées aux cultures vivrières au fil des années avec le développement de l'anacarde. Selon les agronomes, la durée de vie économique est estimée à environ trente ans. Cette immobilisation des sols impacte la production de maïs et peut conduire à des risques de sécurité alimentaire pour les populations de la région compte tenu du fait que le maïs constitue la base alimentaire des sénoufo de ces deux villages de Napié.

\section{IV- Discussion}

La présente étude avait pour objectif de déterminer l'impact des cultures de coton et de l'anacarde sur la celle du maïs dans la sous-préfecture de Napié. Les résultats montrent que l'agriculture de rente génère des profits aux paysans dans le Nord de la Côte d'Ivoire. Ce résultat est en adéquation avec les travaux d'Aïwa (2015). Son étude a relevé que le coton a un impact socio-économique positif sur la région du Nord. Cette spéculation a permis de réduire le niveau de pauvreté dans les villages et d'améliorer l'habitat rural notamment. Pour lui, la culture du coton a favorisé de meilleures conditions de vie des populations grâce à la réalisation d'infrastructures communautaires comme les pistes rurales, les écoles, les dispensaires ruraux etc. Dans le même sens, Sinan et N'dri (2016) ont montré également l'impact socio-économique de la culture d'anacarde sur les producteurs de la sous-préfecture d'Odienné. Cette étude leur a permis de comprendre l'environnement des producteurs de ce secteur d'activité agricole. Les conclusions de leur étude stipulent 
que la culture d'anacardier est incontournable dans cette région de la Côte d'Ivoire à cause de sa rentabilité économique et financière. Les revenus engendrés par cette culture ont permis aux producteurs de subvenir à leurs besoins et d'améliorer leurs conditions et cadre de vie.

En ce qui concerne l'encadrement et la formation, la présente étude note que les producteurs de maïs n'en reçoivent pas formellement. Pourtant, les producteurs de coton et de l'anacarde bénéficient de formations, d'encadrement de proximité et même des subventions en intrants, et en préfinancement pour la production. Ce handicap pour les maïsiculteurs a un impact sur le niveau de production du maïs dans la Sous-Préfecture de Napié. Ce résultat est similaire à l'étude de Rongead (2014). Dans un rapport sur la filière maïs en Côte d'Ivoire, il ressort des travaux de cette structure que la culture du maïs est implantée sur la totalité du territoire du pays mais que cette filière n'a bénéficié jusqu'à présent que de très peu d'actions de promotion et d'encadrement, aussi bien de la part de l'Etat que des partenaires techniques et financiers. En outre, elle manque encore de certaines conditions essentielles à sa modernisation. En effet, la faiblesse du réseau de distribution d'intrants et de l'offre en semences améliorées et adaptées, limitent encore fortement la professionnalisation des producteurs. Cette réalité est vécue par les producteurs de maïs de la zone d'étude. Yeo (2011) abonde dans le même sens. En effet, parlant de la compétitivité de la filière maïs, sont rapport a constaté que malgré les potentialités qu'offrent cette denrée alimentaire, il n'y a aucune politique spécifique envisagée dans ce domaine agricole. Pour lui, le maïs est relégué au second plan. Cela explique l'attitude des agriculteurs qui privilégient d'autres cultures telles que le coton au Nord et le café-cacao au Sud qui sont des secteurs agricoles dans lesquels l'Etat a une politique plus ou moins coordonnée. Il relève également le rôle du Centre National de Recherche Agronomique qui est la structure chargée de la recherche et de la fourniture de semences améliorées. Mais, il note qu'il n'existe aucune structure de distribution « grand public » pour assurer la valorisation des semences issues de ce centre en dehors d'interventions ponctuelles des projets de développement. En outre, l'ANADER, partenaire privilégié du monde rural n'assure ses interventions que dans les domaines agricoles dominants dans chaque région de la Côte d'Ivoire.

Sur la question de l'immobilisation des terres de culture, Silué (2020) démontre que le système de culture basé sur l'anacarde est source d'augmentation de la pression foncière donc à la réduction de terres cultivables. Cette nouvelle dynamique spatiale de l'anacarde modifie également la gouvernance foncière dans la zone dense de Korhogo car elle favorise l'appropriation des espaces de culture. Il conclut que la sécurité alimentaire est menacée dans la mesure où l'accaparement des espace du vivrier au profit de l'anacardier impacte négativement le niveau de production vivrière.

Cependant, les résultats de de l'étude de Schwartz (1999) relativement à l'impact des cultures dites industrielles sur la production des cultures vivrières dans le monde paysan prennent le contre-pied des conclusions de la présente étude. Cet auteur pense que les cultures de rente contribuent de façon positive à l'essor des cultures vivrières. Dans son étude sur l'exemple du Burkina Faso, il ressort que dans les provinces de l'ouest, notamment celle de Kénédoudou qui constituent le bassin cotonnier de ce pays, la production vivrière est plus élevée que celle des autres régions. Il justifie cela par l'effet d'entrainement des intrants, de l'encadrement du coton et surtout la culture attelée qui se pratique dans ces localités productrices de coton graine dans un système de rotation de culture. Ainsi la réduction des espaces culturales dédiés au vivrier et particulièrement le maïs est-elle compensée par les facteurs de production. Pour cet auteur, la culture du coton ne peut donc pas constituer un risque d'insécurité alimentaire.

\section{Conclusion}

Au terme de cette étude, on peut retenir que les cultures de rente que sont le coton et l'anacarde ont un impact sur la production de maïs à Djadonkaha et Pimankaha. Grâce aux aides reçues de la part de l'Etat à travers les structures d'encadrement et de formation comme le Conseil du Coton et de l'Anacarde, du FIRCA et de la COIC, ces filières agricoles jouissent d'une bonne organisation. Les prix d'achat garantis, les préfinancements, les partenaires commerciaux, les revenus etc. expliquent les choix des paysans pour ces cultures. Cette structuration permet aux producteurs de ces denrées d'améliorer leurs conditions de vie, de travail ainsi que leur cadre de vie. Ainsi, les logiques socioéconomiques des agriculteurs sont prépondérantes dans leur choix de culture. Ils choisissent de pratiquer les cultures qu'ils pensent être rentables pour eux et pour leur famille. Pour autant, le caractère pérenne des anacardiers contribuent à 
OUATTARA Nanfouhoro Paul-Kévin et./al La culture du maïs face au binôme coton-anacarde dans le nord ivoirien: Une cohabitation dominée par les cultures de rente dans la Sous-Préfecture de Napié

occuper et à immobiliser de grandes superficies de terre. Ce qui réduit les espaces dédiés aux autres cultures particulièrement à l'agriculture vivrière. Au final, on peut conclure que les difficultés de la filière maïs en général et à Napié en particulier sont en partie la conséquence des choix économiques du pays qui a basé son économie sur les cultures d'exportation. Pour inverser la tendance, il faut que les cultures vivrières bénéficient de la même attention que les cultures industrielles exportation (Schwartz, 1999). Cela doit passer non seulement par la mise en place d'un fonds plus important pour la recherche dans le domaine du vivrier mais surtout dans celui de la maïsiculture en particulier. Cela peut passer également par un changement de paradigme dans les choix des politiques d'encadrement du monde agricole.

\section{References}

1- Agence Ivoirienne de Presse (2018). Des producteurs de-coton du Poro et du Hambol récompensés à Korhogo, publié le 18 Mai 2018. https://news.abidjan.net/articles/637459/des-producteurs-de-cotondu-poro-et-du-hambol-recompenses-a-korhogo

2- AÏWA A. E. (2015). L'impact de la culture du coton sur le développement socio-économique : étude de cas dans la région de Korhogo au Nord de la Côte d'Ivoire. European Scientific Journal. édition vol. $11, \mathrm{~N}^{\circ} 32$.

3- KOFFI Y. J. J. (2015). Une nouvelle culture dans le Nord-est de la Côte d'Ivoire : le roucou (bixaorella) dans le département de Tanda. Germivoire 2/2015.

4- LEROY Y. (2021). La région du Poro enregistre une hausse de sa production d'anacarde. https://www.linfodrome.com/economie/65011-cote-d-ivoire-la-region-du-poro-enregistre-unehausse-dans-la-production-d-anacarde

5- PUGNET V. (2018). fiche pays producteur : la mangue en Côte d'Ivoire. Fruitrop, n²25 Mars/Avril 2018.

6- RONGEAD et ONG CHIGATA (2014). Diagnostic de la filière maïs en Côte d'Ivoire, Projet « redynamiser la production, l'accès au marché et conseil agricole pour les filières vivrières et commerciale du nord de la Côte d'Ivoire. Rapport, novembre 2013-avril 2014.

7- SCHWARTZ A. (1999). Culture du coton, sécuritaire alimentaire et développement durable dans les savanes de l'Afrique Subsaharienne : l'exemple du Burkina Faso. Colloque, éditions Tec et Doc.

8- SILUE K., GBODJE J. A. et DJAKO A. (2020). Dynamique spatiale de l'anacarde et problématique de la sécurité alimentaire dans la zone dense du département de Korhogo (Nord-Côte d'Ivoire). Revue espace géographique et société marocaine. $\mathrm{n}^{\circ} 32$, Février 2020.

9- SINAN A. et N'DRI K. A. (2016). Impacts socio-économiques de la culture d'anacarde dans la souspréfecture d'Odienné. European Scientific Journal. novembre 2018. édition vol. 12, № 32

10- YEO Y. A. (2011). Analyse de la compétitivité de la filière maïs en Côte d'Ivoire. PRESAO. Rapport Final, Novembre 2011. 